\title{
GAMBARAN PENGETAHUAN REMAJA TENTANG PROGRAM GENRE DI SMP NEGERI 2 PENEBEL
}

\author{
Kadek Sri Ariyanti ${ }^{1,2}$, Ni Made Indra Peratiwi ${ }^{1,2}$, Shonia Margareth ${ }^{1,2}$ \\ ${ }^{1}$ Program Studi Diploma III Kebidanan, ${ }^{2}$ STIKES Advaita Medika Tabanan \\ Korespodensi penulis: ariyanthi.midwife@gmail.com
}

\begin{abstract}
Abstrak
Latar belakang: Program GenRe adalah suatu program untuk memfasilitasi terwujudnya tegar remaja, yaitu remaja yang berperilaku sehat, terhindar dari risiko Triad KRR, menunda usia pernikahan, mempunyai perencanaan kehidupan berkeluarga untuk mewujudkan keluarga kecil bahagia sejahtera. Pentingnya dilakukan penelitian tentang program GenRe agar dapat membantu pemerintah dalam menjalankan program kerja untuk menurunkan angka kejadian pernikahan dini, narkoba dan sek bebas.

Tujuan: Mengetahui gambaran pengetahuan remaja tentang program GenRe di SMP Negeri 2 Penebel.

Metode: Jenis penelitian adalah deskriptif dengan rancangan cross-sectional. Penelitian ini dilakukan di SMP Negeri 2 Penebel, pada bulan agustus 2020 dengan Jumlah sample sebanyak 75 siswa yang di ambil secara random. Instrumen yang digunakan adalah kuesioner yang diberikan secara online dengan item pertanyaan 15 soal dan analisis data menggunakan analisis univariat.

Hasil: gambaran pengetahuan remaja tentang program GenRe di SMP Negeri 2 Penebel sebagian besar dalam katagori baik yaitu 62 responden sebanyak $(82,7 \%)$.

Simpulan : Gambaran pengetahuan remaja tentang program GenRe sebagian besar dalam kategori baik.
\end{abstract}

Kata kunci: Pengetahuan, Program GenRe, Remaja

\section{Pendahuluan}

Masa remaja merupakan masa peralihan dari masa kanak-kanak ke masa dewasa. Menurut WHO (World Health Organization) batasan usia remaja adalah 10 tahun hingga 19 tahun. Batasan usia remaja yang digunakan oleh BKKBN adalah 10-24 tahun dan belum menikah. Sedangkan menurut Peraturan Menteri Kesehatan No 25 tahun 2014, batasan usia remaja adalah 10 tahun hingga 18 tahun. Jumlah Penduduk usia remaja (10-24 tahun) sangat besar yakni mencapai $27,6 \%$ dari seluruh penduduk yang ada di Indonesia (BPS, 2013).

Jumlah remaja yang sangat besar, maka perlu dilaksanakan upaya dalam rangka mempersiapkan remaja menjadi manusia yang sehat secara jasmani, rohani, mental sosial dan spiritual (BKKBN, 2014). Hal yang perlu diwaspadai terkait dengan meningkatnya jumlah remaja adalah muculnya berbagai permasalahan yang terkait dengan remaja. Permasalahan yang paling banyak terjadi pada remaja adalah tingginya persentase pernikahan usia dini yakni sebesar $44,70 \%$. Pengetahuan remaja tentang KRR (kesehatan reproduksi remaja) masih rendah, yakni sebesar $48,4 \%$ pada survei RPJMN (rencana pembangunan jangka menegah nasional) 2014 dan sedikit meningkat pada tahun 2015 menjadi 49\%. Tahun 2016 turun drastis menjadi 32,2\% (BKKBN, 2017).

Menurut Kemenkes RI tahun 2015, Indonesia menempati peringkat 37 di dunia dalam hal pernikahan usia muda serta tertinggi kedua di ASEAN setelah kamboja. Hasil Riset Kesehatan Dasar (Riskesdas) 
tahun 2013 menunjukkan bahwa di Indonesia data pernikahan dini sudah cukup tinggi yaitu $4,8 \%$ pada usia $10-14$ tahun dan $41,9 \%$ pada usia 15-19 tahun. Pernikahan usia dini sering diawali dengan terjadinya kehamilan.

Berdasarkan Data Age Spesific Fertility Rate (ASFR) di Bali ditemukan bahwa kehamilan remaja pada usia dini cukup tinggi. Remaja yang hamil usia $<20$ tahun ditemukan sebanyak 653 jiwa, Daerah Kabupaten Tabanan berada pada peringkat empat di Provinsi Bali dalam hal remaja yang hamil usia $<20$ tahun, sebanyak 71 jiwa (Dinas Kesehatan Provinsi Bali, 2017). Data perkawinan di Kabupaten Tabanan pada usia $<21$ tahun terdapat 1854 jiwa. Jumlah lakilaki yang menikah usia $<21$ tahun 447 jiwa dan perempuan 1407 jiwa. Data pernikahan usia $<21$ tahun lebih banyak ditemukan pada perempuan, hal tersebut di karenakan perempuan menikah dengan pasangannya yang berusia $>21$ tahun (Dinas Pendudukdan Catatan Sipil, 2017). Hasil dari studi pendahuluan bahwa data kehamilan yang cukup tinggi pada remaja yang berusia $<20$ tahun tentunya akan beresiko tinggi pada kesehatan ibu dan bayi.

Program GenRe diharapkan dapat memberikan pengetahuan dan pemahaman mengenai berperilaku sehat, menunda usia pernikahan, mempunyai perencanaan kehidupan berkeluarga untuk mewujudkan keluarga kecil sejahtera. Hal ini diharapkan dapat menekan angka kematian ibu dan anak terutama bagi kaum remaja sekolah yang melakukan pernikahan dini (BKKBN, 2012).

Pengetahuan remaja tentang GenRe sangat penting mengingat program generasi berencana untuk meningkatkan kesehatan remaja. Saat ini usia perkawinan semakin muda (pernikahan dini), remaja usia
SMP/SMA sudah menjadi seorang ayah atau ibu. Cara fisik dan psikologis, mereka belum matang sehingga rentan mengalami masalah dalam rumah tangga baik kesehatan maupun masalah sosial ekonomi (Sarwono, 2012). Oleh karena itu, penelitian melakukan penelitian dengan judul "Gambaran Pengetahuan Remaja Tentang Program GenRe Di SMP Negeri 2 Penebel Tahun 2020" meliput pengertian, tujuan dan strategi program GenRe.

\section{Metode Penelitian}

Penelitian ini menggunakan metode deskriptif kuantitatif. Pendekatan yang digunakan adalah pendekatan crosssectional, karena tujuan penelitian utama dari penelitian ini untuk gambaran tentang penelitian suatu keadaan secara obyektif yang dilakukan hanya satu kali terhadap sekumpulan obyek yang biasanya cukup dalam jangka waktu tertentu (Notoatmodjo,2002).

Lokasi penelitian ini dilakukan di SMP Negeri 2 Penebel. Waktu pengambilan dilaksanakan pada bulan Agustus 2020. Sample penelitian ini adalah siswa SMP Negeri 2 Penebel yang berjumlah 75 siswa. Teknik sampling yang digunakan dalam penelitian ini adalah simple random sampling yaitu suatu teknik penetapan sampel yang dilakukan secara acak tanpa memperhatikan strata yang ada dalam populasi. Sampel tersebut dapat mewakili karakteristik populasi yang telah dikenal sebelumnya (Nursalam, 2017).Dalam penelitian ini analisis univariat yang dilakukan adalah mendistribusikan karakteristik responden yaitu umur, pendidikan dan pekerjaan serta mendistribusikan gambaran pengetahuan.

\section{Hasil dan Pembahasan}

Tabel 1. Karakteristik Responden

\begin{tabular}{llll}
\hline No & Karakteristik responden & Frekuensi (f) & Presentase (\%) \\
\hline & Umur & & \\
2 & $11-12$ & 7 & 9,3 \\
3 & $13-14$ & 4 & 5,3 \\
Total & $15-16$ & 64 & 85,3 \\
\hline
\end{tabular}




\begin{tabular}{llll}
\hline & Kelas & & \\
1 & VII & 26 & 34,7 \\
2 & VIII & 20 & 26,7 \\
3 & IX & 29 & 38,7 \\
Total & & 75 & 100,0 \\
\hline & Informasi GenRe & & \\
1 & Pernah & 45 & 60,0 \\
2 & Tidak Pernah & 30 & 40,0 \\
Total & & 75 & 100,0 \\
\hline & Sember informasi GenRe & & \\
1 & Petugas kesehatan & 35 & 46,7 \\
2 & Teman/saudara & 11 & 14,7 \\
3 & Media elektronik & 12 & 16,0 \\
4 & Majalah/koran & 8 & 10,7 \\
5 & Guru & 9 & 12,0 \\
Total & & 75 & 100,0 \\
\hline
\end{tabular}

Tabel 2 Distribusi frekuensi responden berdasarkan pengetahuan siswa remaja SMP Negeri 2 Penebel

\begin{tabular}{|c|c|c|c|}
\hline No & Pengetahuan GenRe & Frekuensi (f) & Presentase (\%) \\
\hline $\begin{array}{l}1 \\
2 \\
\text { Total }\end{array}$ & $\begin{array}{l}\text { Program GenRe } \\
\text { Tahu } \\
\text { Tidak tahu }\end{array}$ & $\begin{array}{l}62 \\
13 \\
75\end{array}$ & $\begin{array}{c}82,7 \\
17.3 \\
100,0\end{array}$ \\
\hline $\begin{array}{l}1 \\
2 \\
\text { Total }\end{array}$ & $\begin{array}{l}\text { Pengertian } \\
\text { Tahu } \\
\text { Tidak tahu }\end{array}$ & $\begin{array}{l}60 \\
15 \\
75\end{array}$ & $\begin{array}{c}80,0 \\
20,0 \\
100,0 \\
\end{array}$ \\
\hline $\begin{array}{l}1 \\
2 \\
\text { Total }\end{array}$ & $\begin{array}{l}\text { Tujuan } \\
\text { Tahu } \\
\text { Tidak tahu }\end{array}$ & $\begin{array}{l}50 \\
25 \\
75 \\
\end{array}$ & $\begin{array}{c}66,7 \\
33,3 \\
100,0 \\
\end{array}$ \\
\hline $\begin{array}{l}1 \\
2 \\
\text { Total }\end{array}$ & $\begin{array}{l}\text { Strategi } \\
\text { Tahu } \\
\text { Tidak tahu }\end{array}$ & $\begin{array}{l}51 \\
24 \\
75 \\
\end{array}$ & $\begin{array}{c}68,0 \\
32,0 \\
100,0 \\
\end{array}$ \\
\hline
\end{tabular}

Dari Tabel 1 dapat dilihat bahwa dari 75 responden, sebagian besar responden berusia 15-16 tahun yaitu sebanyak 64 responden $(85,3 \%)$, sebagian besar responden dari kelas IX yaitu sebanyak 29 responden $(38,7 \%)$, sebagian besar responden pernah mendengar tentang program GenRe dan sebagian besar responden bersumber dari tenaga kesehatan.

Berdasarkan tabel 4.2 bahwa dari 75 responden pengetahuan tentang pengertian program GenRe pada remaja di SMP Negeri 2 Penebel yaitu sebanyak 60 responden $(80,0 \%)$, pengetahuan tentang tujuan program GenRe pada remaja di SMP Negeri 2 Penebel yaitu sebanyak 50 responden $(66,7 \%)$ dan pengetahuan tentang strategi program GenRe pada remaja di SMP Negeri 2 Penebel sebanyak 51 responden $(68,0 \%)$.

Sebagian besar responden dengan kelompok umur 15-16 tahun yaitu 64 orang $(85,3 \%)$ memiliki pengetahuan yang lebih, ini sesuai dengan teori menurut Mubarak (2011) Umur mempengaruhi terhadap daya tangkap dan pola pikir seseorang. Dengan bertambahnya umur individu, daya tangkap dan pola pikir seseorang akan lebih berkembang, sehingga pengetahuan yang diperolehnya semakin membaik.

Menurut Notoadmojo (2012) umur seseorang semakin tua maka proses perkembangan mentalnya bertambah baik. Umur sangat berpengaruh pada pengetahuan, umur yang cukup memiliki pola pikir dan 
pengalaman yang matang sehingga pengetahuan yang diperolehnya semakin baik.

Paling banyak responden dari kelas IX yaitu 29 orang $(38,7 \%)$, sesuai dengan teori menurut Mubarak (2011) bahwa pendidikan merupakan suatu usaha untuk mengembangkan kepribadian dan kemampuan seseorang agar dapat memahami suatu hal. Pendidikan mempengaruhi proses belajar, semakin tinggi pendidikan seseorang, semakin mudah orang tersebut menerima informasi. Pengetahuan sangat erat kaitannya dengan pendidikan dimana diharapkan seseorang dengan pendidikan tinggi, maka orang tersebut akan semakin luas pengetahuannya.

Menurut Notoadmojo (2012) suatu usaha untuk mengembangkan kepribadian dan kemampuan di dalam dan di luar sekolah dan berlangsung seumur hidup. Pendidikan mempengaruhi proses belajar, makin tinggi pendidikan seeorang makin mudah orang tersebut untuk menerima informasi.

\section{Simpulan}

Simpulan penelitian ini adalah gambaran pengetahuan remaja di SMP Negeri 2 Penebel sebagian besar dalam katagori baik yaitu sebanyak 62 responden $(82,7 \%)$.

\section{Referensi}

Arikunto, S. 2006. Prosedur Penelitian Suatu Pendekatan Proses Edisi Revisi. Jakarta : Rineka Cipta.

Aziza, SP, MP TN, Itcianday I. Peranan "INCAR" (Informasi Cerdas Ala Remaja)

Dalam Program GenRe (Generasi Berencana) di Kabupaten Nunukan. J Borneo Adm. 2018.

BKKBN. 2017a. Survei Iendikator Kinerja Program KKBPK RPJMN Keluarga. Jakarta: Badan Kependudukan dan Berencana Nasional.

BKKBN. 2017b. Survei Kependudukan, Keluarga Berencana, Kesehatan Reproduksi Remaja dan
Pembangunan Keluarga di Kalangan Remaja Indonesia. Jakarta: Badan Kependudukan dan Berencana Nasional.

BKKBN Provinsi Jawa Timur. 2014. GenRe Generasi Berencana. Surabaya: Perwakilan Badan Kependudukan dan Keluarga Berencana Nasional Provinsi Jawa Timur.

Desiyanti, I.W. 2015. Faktor-Faktor yang Berhubungan Terhadap Pernikahan Dini Pada Pasangan Usia Subur di Kecamatan Mapanget Kota Manado. Jikmu, [e-journal] 5 (2), pp. 270-280.

Hayati, E., Amir, P., Asfriyati. 2016. Pengaruh Komunikasi Persuasif Bidan Terhadap Pengetahuan dan Sikap Ibu Tentang Pemberian MPASI Di Desa Pasar Maga Kecamatan Lembah Sorik Merapi Kabupaten Mandailing Natal Tahun 2016.

Indah,Firdayanti N. Icite \{Annisa2016,IndahFirdayanti201

9,Unknown\}. J Widwifery. 2019.

Jurnal Penelitian Pendidikan Sosial Humaniora, [e-journal] 1 (2): pp. 72 79. Lago, M.N. 2017. Eksploitasi Tubuh Perempuan Di Media Televisi (Analisis Semiotika Makna Pesan Iklan Cat Avian Syntetic Versi Awas Cat Basah). Jurnal Online Kinesik, [e-journal] 30 (2): pp. 30-36.

Rachma AA. Gambaran Tingkat Pengetahuan Remaja Tentang Kebersihan

Organ Genitalia Eksterna Di Sman 90 Jakarta.; 2016.

Tanjung RDS. Analisis Pengetahuan Remaja Tentang Program Generasi

Berencana Di Smu Negeri 1 Marbau Tahun 2018.

Notoatmodjo, S. 2010. Metodologi Penelitian Kesehatan. Jakarta : Rineka Cipta.

Notoatmodjo S. 2007. Promosi kesehatan dan ilmu perilaku. Rineka cipta: Jakarta.

Notoatmodjo, S. 2014. Ilmu Perilaku Kesehatan. Jakarta: Rineka Cipta 